\title{
Insight into maternal mortality of tertiary referral hospital of Madhya Pradesh: destination far ahead
}

\author{
Bharti Sahu*, Padma Shukla, Shama Khan, Parwati Sharma
}

Department of Obstetrics \& Gynaecology, N.S.C.B Medical College and Hospital, Jabalpur, M.P., India

Received: 12 July 2015

Revised: 25 August 2015

Accepted: 14 August 2015

\author{
*Correspondence: \\ Dr. Bharti Sahu, \\ E-mail: arvindsahu15@yahoo.com
}

Copyright: (c) the author(s), publisher and licensee Medip Academy. This is an open-access article distributed under the terms of the Creative Commons Attribution Non-Commercial License, which permits unrestricted non-commercial use, distribution, and reproduction in any medium, provided the original work is properly cited.

\begin{abstract}
Background: Demise of mother wreaks havoc in family, society and ultimately nation. Amongst so many countries, India alone contributes one quarter of total world maternal deaths. Millennium Development Goal targeted to cut down maternal mortality up to or less than 109 per lakh of total live births is far away from present level prevailing especially in our institution of Madhya Pradesh in centre of India.

Methods: A retrospective analysis of maternal deaths from hospital records and death summaries of one year between Jan 2014 to Dec 2014 at NSCB Medical College and Hospital, Jabalpur in Madhya Pradesh.

Results: During the review period, there were 75 maternal deaths and 5509 live births. (Institutional maternal mortality ratio, 1361.1 per lakh live births). All cases were analysed in detail: $70.6 \%(\mathrm{n}=53)$ were direct maternal deaths and PIH $(n=34,45.33 \%)$ and Haemorrhage and sepsis $(n=7,9.33 \%)$ were the leading causes of mortality. In indirect causes $29.33 \%(\mathrm{n}=22)$, severe anaemia topped $(\mathrm{n}=14,18.66 \%)$. Women frequently did not attend prenatal clinics $(n=73,97.33 \%)$, were resident of rural areas $(n=67,89.33 \%)$, referred $(n=68,90.66 \%)$ most of them were of age of 20-30 years $(n=64,82 \%)$ primigravida $(n=45,60 \%), 70 \%$ postnatal and experienced delays in care $(n=$ $41,44.66 \%)$ and lost battle of life within 24 hrs. of admission.

Conclusions: The burden of maternal mortality was found to be unacceptably high. Most women died of direct causes and experienced delays in care. Improvement in the quality of skilled maternity care, utmost need to avail good, proper and effective antenatal care, timely referral, prompt transportation, provision of family planning services, among other factors, can drastically curtail the maternal deaths.
\end{abstract}

Keywords: Maternal mortality, Antenatal care, Emoc, MDG.

\section{INTRODUCTION}

GOD could not be present everywhere so he made mothers and why should these mothers die during natural process of giving birth. Pregnancy should culminate into healthy mother and healthy baby. Between 1990 and 2010, maternal mortality worldwide dropped by almost $50 \%$ but still it is very high. Almost all maternal deaths $(99 \%)$ occur in developing countries. ${ }^{1,2}$ India is among those countries, which has a high maternal mortality ratio. Maternal mortality varies from state to state and region to region in India itself. Maternal mortality ratio is a vital index of the effectiveness of prevailing obstetric services and socioeconomic affluence of a country. ${ }^{3}$ It also reflects the educational and public health consciousness of a country. Institutional mortality rates are 2-10 times higher as compared with field surveys because most of the seriously ill patients are referred to the nearest tertiary care centre. ${ }^{3}$ The Government of India is committed and struggling to tackle the health and mortality statistics of the rural poor, and of the scheduled caste and tribal peoples, which significantly contribute to the global mortality rates of mothers and children under the age of 5 years. ${ }^{4}$ 
Hence, this present study was conducted to review the existing maternal mortality ratio and the causes of maternal death at a tertiary care teaching hospital in central India. So that, corrective measures can be taken to reach the goal within the stipulated time frame as most of these deaths if timely intervened are very much preventable.

\section{METHODS}

The present study is a retrospective study of Maternal Mortality occurred at Obstetrics and Gynaecology Department of Netaji Subhash Chand Bose Government Medical College and Hospital, Jabalpur a tertiary level health care referral centre in Madhya Pradesh. In this study, "maternal death" defined according to the tenth revision of International Classification of Diseases (ICD10) by WHO. It is described as the death of a woman while pregnant or within 42 days of termination of pregnancy, irrespective of the duration and the site of the pregnancy, from any cause related to or aggravated by the pregnancy or its management, but not from accidental or incidental causes. All maternal deaths of 75 during the period of a year from 1st Jan 2014 to 31st Dec 2014 were analysed with the special emphasis on cause of death.

In the critical study of maternal mortality the details were recorded in the designed proforma \&influences of variables such as age, parity, marital status, age at marriage, booked vs. unbooked, geographical location, educational status, socio-economic status, time interval since admission, mode of delivery, causes of death and various other factors have also been considered. Results were analysed by using proportion and percentage.

\section{RESULTS}

Total no. of live births during the study period was 5509 while total no. of maternal deaths was 75. Maternal Mortality Ratio was 1361.1/ 1, 00,000 live births.

Table 1: year wise maternal deaths and live birth.

\begin{tabular}{|ll|}
\hline Year & MMR \\
\hline 2010 & 1754.38 \\
\hline 2011 & 1373.22 \\
\hline 2012 & 2090.42 \\
\hline 2013 & 1356 \\
\hline 2014 & 1361.40 \\
\hline
\end{tabular}

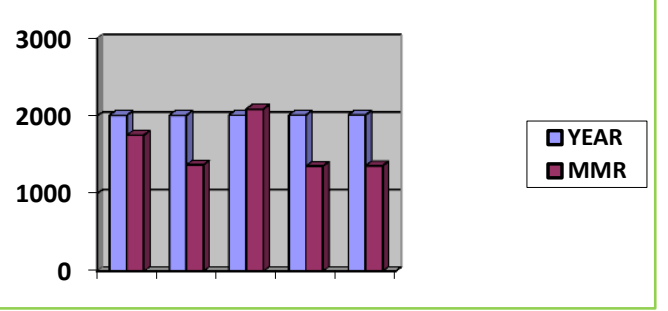

Figure 1: 1 year wise maternal deaths and live birth.
Table 2: MMR in relation to age.

\begin{tabular}{|l|l|l|}
\hline A ge group & No. of cases 75 & Percent \\
\hline$<20$ yrs. & 7 & $9.3 \%$ \\
\hline $20-30$ yrs. & 64 & $85 \%$ \\
\hline $30-40$ yrs. & 4 & $5 \%$ \\
\hline$>40$ yrs. & 0 & $0 \%$ \\
\hline
\end{tabular}

It is noted that out of 75 maternal deaths during the study period, 7 deaths $(9.3 \%)$ have occurred in the age group of less than 20 years. 64 deaths $(85 \%)$ have occurred in the age Group 20- 30 years.

Table 3: MMR in relation to demographic profile.

\begin{tabular}{|lll|}
\hline $\begin{array}{l}\text { Demographic } \\
\text { profile }\end{array}$ & $\begin{array}{l}\text { Number of } \\
\text { cases }\end{array}$ & Percent \\
\hline Booked & 2 & $2.6 \%$ \\
\hline Unbooked & 73 & $97.33 \%$ \\
\hline Rural & 67 & $89.33 \%$ \\
\hline Urban & 8 & $10.66 \%$ \\
\hline Direct & 7 & $9.33 \%$ \\
\hline Referred & 68 & $90.66 \%$ \\
\hline
\end{tabular}

During the study period, out of the total 75 cases, 73 cases $(97.33 \%)$ were unhooked and received no or inadequate antenatal care either in terms of the quality of care or the number of visits and 2 cases (2.6\%) were booked cases. The rural population is at greater risk with regard to maternal death. During the study period, about 67 deaths $(89.33 \%)$ have occurred in rural population compared to 8 deaths $(10.66 \%)$ which have occurred in urban population. This geographical location is significantly associated with MMR. Majority of cases 68 $(90.66 \%)$ were referred to our institute.

Table 4: MMR in relation to gravid status.

\begin{tabular}{|lll|}
\hline Gravida & Number of Cases & Percent \\
\hline G1 & 45 & $60 \%$ \\
\hline G2 & 19 & $25.33 \%$ \\
\hline G3 & 6 & $8 \%$ \\
\hline G4 & 4 & $5.33 \%$ \\
\hline$>$ G4 & 1 & $1.33 \%$ \\
\hline
\end{tabular}

It was noted that out of 40 deaths during the study period, 45 deaths $(60 \%)$ have occurred in primigravida, 19 deaths $(25.33 \%)$ have occurred in gravida 2 and 6 deaths $(8 \%)$ have occurred in gravida 3 and 4 deaths $(5.33 \%)$ have occurred in gravida 4.

Majority of the subjects, i.e. $44.66 \%$ died within $24 \mathrm{~h}$ of admission to the hospital and within $72 \mathrm{hrs}$ of admission total $73 \%$ of cases lost their life.

Amongst the direct causes 53 subjects i.e. (70.66\%), eclampsia and pre-eclampsia together accounted for 
$45.33 \%$ of the deaths, while obstetric hemorrhage and sepsis stood second at $9.33 \%$.

Table 5: MMR in relation to admission-death time interval.

\begin{tabular}{l|l|l|}
$\begin{array}{l}\text { Duration of stay in } \\
\text { hospital }\end{array}$ & No of cases 75 & $\%$ \\
\hline$<12$ Hrs. & 29 & $38.66 \%$ \\
\hline $12-24$ Hrs. & 12 & $16 \%$ \\
\hline $24-72$ Hrs. & 17 & $22.66 \%$ \\
\hline 72 Hrs.-5 Days & 6 & $8 \%$ \\
\hline >5 Days & 11 & $14 \%$ \\
\hline
\end{tabular}

Table 6: Direct Cause of MMR.

\begin{tabular}{|l|l|l|}
\hline Direct Causes & 53 & Percent \\
\hline Eclampsia & 28 & $30.66 \%$ \\
\hline Pre-Eclampsia & 6 & $87.33 \%$ \\
\hline Obstructed labour & 5 & $6.66 \%$ \\
\hline Sepsis & 7 & $9.33 \%$ \\
\hline Hemorrhage & 7 & $9.33 \%$ \\
\hline
\end{tabular}

$44.66 \%$, subjects gave up their battle with life within 24 $\mathrm{h}$ of hospital admission and within $72 \mathrm{~h}$ up to $66.60 \%$ succumbed. Other studies have reported an incidence ranging from 54 to $70 \% .^{3}$ The subjects or more truly, their families, compounded by poor transportation, bring them late to the hospitals, and very little time for positive intervention is available In the study by Verma Ashok et al, $46.15 \%$ of maternal deaths occurred within 24 hours also in Dilpreet Kaur et al study maximum maternal deaths $(48.10 \%)$ occurred within $24-48 \mathrm{~h}$ of admission. ${ }^{7,9}$ Table 6 Direct death 53\%,of them, toxemia $(45.33 \%)$, hemorrhage $(9.33 \%)$ and sepsis $(9.33 \%)$ are all preventable by high risk screening and proper antenatal, intranatal and emergency obstetric care (EmOC). The deaths due to eclampsia are very high in our study. This is mainly because many patients come to our hospital without any $\mathrm{Bp}$ checkup ever before or during their pregnancy. Early referral to a higher center would have helped these patients these were probably avoidable deaths if pregnancy was terminated early. In study by Das et al, direct cause contributed to $81.64 \%$ of maternal deaths, amongst them, $43.75 \%$ were due to eclampsia. ${ }^{1,2}$ Hemorrhage and sepsis were responsible for $21.87 \%$ and $13.28 \%$ of deaths comparable to our study. Table 7 , in the present study, $18.66 \%$ of maternal deaths were because of anemia which co relates with the results from Panda et $\mathrm{al}^{10}$ and Verma et al, pre-existing anemia worsens as pregnancy advances leading to congestive heart failure and death. ${ }^{7}$ It also impedes the mother's ability to resist infection or cope with hemorrhage and increases the likelihood of her dying in childbirth by a factor of four. Amongst the indirect causes anemia being the major cause of death is absolutely preventable by iron, folic acid, protein supplement, antihelmenthics, revealing the dismal nature of primary prevention from childhood through adolescence into pregnancy. Availability of better antibiotics on demand (below poverty line card holders are provided free medicines by the Government under different schemes) has resulted in lesser number of subjects dying of infection. Similarly, good blood banking and transfusion services have shown a positive impact in reducing mortality due to obstetric hemorrhage (Table 6). For the above reasons as well as due to better diagnostic modalities, death from ectopic pregnancy and abortions has also significantly decreased. This is due to increasing awareness about contraception, legal abortion services and better methods and drugs for abortion and prophylactic antibiotic use.

Although more pregnant women are accessing the health services, lack of adequately trained and motivated personnel at the sites probably resulted in the unfortunate women being picked up and referred late to a tertiary center. For each pregnant woman who dies, there remain a countless number of those who suffer from short- or long-term morbidities. Preventive obstetrics has taken a backseat to the sole target of institutional deliveries providing financial incentives to the patients' family and health care providers irrespective of the outcome of pregnancy.

Amongst the direct causes 53 subjects i.e. (70.66\%), eclampsia and pre-eclampsia together accounted for $45.33 \%$ of the deaths, while obstetric hemorrhage and sepsis stood second at $9.33 \%$.

Table 7: Indirect Causes of MMR.

\begin{tabular}{|l|l|l|} 
Indirect causes & 22 & $29.33 \%$ \\
\hline Severe anemia & 14 & $18.66 \%$ \\
\hline Hepatitis & 1 & $1.33 \%$ \\
\hline Heart disease & 2 & $2.66 \%$ \\
\hline Malaria & 1 & $1.33 \%$ \\
\hline B t reaction & 0 & $0 \%$ \\
\hline Unrelated & 4 & $5.33 \%$ \\
\hline
\end{tabular}

Amongst the indirect killers (29.33\%), anemia topped at $18.66 \%$. $28 \%$ died undelivered and $72 \%$ died in the postnatal period.

\section{DISCUSSION}

NSCB Medical College and Hospital is situated on the outskirts of Jabalpur city and it caters population from approximately $300 \mathrm{kms}$ periphery. The tertiary care hospitals, regrettably, receives usually complicated and referred cases, sometimes, the patients are admitted only during the terminal stages of their illness, giving MMR of our institute in 2014 of 1361.1 per 1,00,000 live birth (which is much higher than the national average 190). This may be the reason for such an inflated MMR like other teaching institutions of India. The maternal mortality rate at teaching hospitals in India is very high 
and varies from 3778 (Allahabad U.P.) to 215 (Trivandrum, Kerala) per 100,000 live births. Dr. R. V. Bhatt, 2000 shows an MMR of 30.9 per 100,000 births in over 41000 private sector deliveries. Unfortunately, Janani Suraksha Yojana has put an extra load on institutional deliveries without making as earnest an effort to promote the dire need of good antenatal care in reducing maternal morbidity and mortality. While the total number of institutional deliveries has steadily increased, simply those women who were dying at home or in primary or secondary health care centre are rushed in a very critical state taking their last breath in hospitals with the MMR aiming skyward. Death of mother is a tragic event. The young surviving children left motherless, are unable to cope with daily living and are at an increased risk of death. It is heartening to note that MMR is showing a good reduction during the last 2 years at our centre (Table 1). From this study it is evident that proper health care in our hospital helps in reduction of maternal mortality, but further reduction requires better health facilities in remote and rural areas. Table 2 shows $85 \%$ maternal deaths were observed in the age group of 21-30 yrs. Begum et al and Shah et al also reported high mortality in age group of 21-30 yrs. ${ }^{5,6}$ Table 3 The high percentage of deaths in unbooked cases indicates the importance of adequate antenatal care. In studies by Kaur et al, Pal et al and Verma et al more than $80 \%$ maternal deaths were unbooked..$^{7-9}$ The quality of the care is also very important as the facilities may lack even the most basic resources like the drugs, the means to measure the blood pressure and haemoglobin. Most of the mothers live in rural areas. Besides poor resources of health facilities in these areas; women lack awareness of the seriousness of the problems they may land into. $97.33 \%$ of the subjects dying received no or inadequate antenatal care (ANC), $90.6 \%$ in Kulkarni and Huligol study were unbooked. $^{3}$ This does not imply that fewer pregnant women are receiving ANC, but that, those women who comply with their prescribed plan of ante natal care are rescued from the tragedy of death (Table 4). In the present study $60 \%$ of maternal deaths were primigravida which is comparable to study by Panda et al. In Tables 24 , profiles implying that our poor village girls are still married early and die young, maternity remaining a preventable cause of these tragic deaths. Kulkarni and Huligol and the ICMR task force study reported an almost similar demographic profile. ${ }^{3,10}$ Poverty, illiteracy, unawares and casual acceptance of child bearing together with a shortage of trained and most importantly, dedicated health professionals remain a major hurdle in providing good antenatal care.

\section{CONCLUSIONS}

Over the decades, despite government efforts, the decline in MMR has been slow especially in our vicinity. Much need to be done for maternal health care in rural areas as most of the deaths reported are referrals from peripheral centres. These studies shows first delay and second delay were responsible for maximum preventable and treatable direct deaths. There should be a good health communication system between health centres at urban slums and tertiary care centre. It is necessary even in tertiary centres to channel the working of emergency obstetric care.by which $40 \%$ MMR can be bought down. Death reviews to be attended by all personnel (health and administrative; public and private) [13] involved in the care of pregnant women should be held, and accountability discussed and fixed (presently, there is no such system in place) Taking appropriate remedial steps for filling lacunaes noted in the management of these cases will be of paramount value in reducing the maternal mortality. If the trend persists, we may be derailed from the track in achieving the Millennium Development Goal 5 with respect to maternal mortality. Instituting integrated maternal health services with emphasis on primary health care and emergency obstetric care and holistic approach including literacy, nutrition and social and economic empowerment can achieve remarkable improvement and shed the burden of MMR from INDIA.

\section{Funding: No funding sources}

Conflict of interest: None declared

Ethical approval: The study was approved by the Institutional Ethics Committee

\section{REFERENCES}

1. Countdown to 2015 for maternal, newborn and child survival: accountability for maternal, newborn and child survival. Geneva: Who Health Organization, 2013.

2. Trends in maternal mortality: 1990-2010 - estimates developed by WHO, UNICEF, UNFPA and the World Bank, 2012.

3. Kulkarni SR, Huligol A. Maternal mortality: 10 years study. J Obstet Gynecol India. 2001;51:73-6.

4. World Health Organization \& Unicef. Countdown to 2015 Decade Report (2000-2010): Taking Stock of Maternal, Newborn and Child Survival. Geneva: WHO and UNICEF, 2010.

5. Begum S, Aziz-un-Nisa, Begum I. Analysis of maternal mortality in a tertiary care hospital to determine causes and preventable factors. J Ayub Med Coll., Abbottabad. 2003;15:49-52.

6. Shah RJ, Ali I, Banday A, Fazili A, Khan I, Analysis of maternal mortality in a small teaching hospital attached to tertiary care hospital (a $10 \mathrm{yr}$ review), Department of Community Medicine, S. K. Institute of Medical Sciences, Srinagar, India. 2008;33(4):260-2.

7. Kaur D, Kaur V, Yuel VI. Alarmingly high maternal mortality in 21st century. JK Science. 2007;9(3):1236.

8. Pal A, Ray P, Hazra S, Mondal TK. Review of changing trends in maternal mortality in a rural medical college in West Bengal. J Obstet Gynecol India 2005;55(6):521-4. 
9. Verma A, Minhas S, et al. A study on Maternal Mortality,H.P. J Obstet Gynecol India. 2008;28:2269.

10. Panda SN, Bandyopadhyay S. The 6th World Congress and 14th Indian Conference on Reproductive and Child Health Care. Held at New Delhi from $20^{\text {th }}$ to 22nd, September 2002, organized by the National Association for Reproductive and Child Health of India Delhi Branch a Study on Septic Abortion at a Tertiary Hospital.

11. Bedi N, Kambo I, Dhillon BS, et al. Maternal deaths in India-preventable tragedies (An ICMR Task
Force Study) J Obstet Gynecol India. 2001;51:8692.

12. Das R, Biswas S, Mukherjee A. Maternal Mortality at a Teaching Hospital of Rural India; A Retrospective Study. International Journal of Biomedical and Advance Research, 2014.

13. Veille J-C. Maternal mortality. Prog Obstet Gynaecol. 2008;18:125-42.

Cite this article as: Sahu B, Shukla P, Khan S, Sharma S. Insight into maternal mortality of tertiary referral hospital of Madhya Pradesh: destination far ahead. Int J Reprod Contracept Obstet Gynecol 2015;4:1339-43. 